\title{
Medroxyprogesterone Reverses Tolerable Dose Metformin-Induced Inhibition of Invasion via Matrix Metallopeptidase-9 and Transforming Growth Factor- $\beta 1$ in KLE Endometrial Cancer Cells
}

\author{
Dong Hoon Suh ${ }^{1}$, Sunray Lee ${ }^{2}$, Hyun-Sook Park ${ }^{2}$ and Noh Hyun Park ${ }^{3, *}$ \\ 1 Department of Obstetrics and Gynecology, Seoul National University Bundang Hospital, 82, \\ Gumi-ro 173 Beon-gil, Bundang-gu, Seongnam-si, Gyeonggi-do 13620, Korea; sdhwcj@naver.com \\ 2 Cell Engineering for Origin Research Center, Ujeongguk-ro, Jongno-gu, Seoul 03150, Korea; \\ sunray@naver.com (S.L.); hspark@cefobio.com (H.-S.P.) \\ 3 Department of Obstetrics and Gynecology, Seoul National University College of Medicine, \\ 101 Daehak-ro Jongno-gu, Seoul 03080, Korea \\ * Correspondence: pnhkhr@snu.ac.kr; Tel.: +82-2-2072-3166
}

Received: 6 September 2020; Accepted: 3 November 2020; Published: 6 November 2020

\begin{abstract}
This study was performed to evaluate the anticancer effects of tolerable doses of metformin with or without medroxyprogesterone (MPA) in endometrial cancer cells. Cell viability, cell invasion, and levels of matrix metallopeptidase (MMP) and transforming growth factor (TGF)- $\beta 1$ were analyzed using three human endometrial adenocarcinoma cell lines (Ishikawa, KLE, and uterine serous papillary cancer (USPC)) after treatment with different dose combinations of MPA and metformin. Combining metformin $(0,100,1000 \mu \mathrm{M})$ and $10 \mu \mathrm{M}$ MPA induced significantly decreased cell viability in a timeand dose-dependent manner in Ishikawa cells, but not in KLE and USPC cells. In KLE cells, metformin treatment alone significantly inhibited cell invasion in a dose-dependent manner. The inhibitory effect of metformin was reversed when $10 \mu \mathrm{M}$ MPA was combined, which was significantly inhibited again after treatment of MMP-2/9 inhibitor and/or TGF- $\beta$ inhibitor. Changes of MMP-9 and TGF- $\beta 1$ according to combinations of MPA and metformin were similar to those of invasion in KLE cells. In conclusion, the anticancer effects of tolerable doses of metformin varied according to cell type and combinations with MPA. Anti-invasive effect of metformin in KLE cells was completely reversed by the addition of MPA; this might be associated with MMP-9 and TGF- $\beta 1$.
\end{abstract}

Keywords: metformin; medroxyprogesterone; endometrial cancer; invasion; matrix metallopeptidase-9; transforming growth factor- $\beta 1$

\section{Introduction}

Uterine corpus cancer was found to be the 4 th most common cancer in women in 2018; the estimated number of new cases was 63,230 , accounting for $7 \%$ of all new cancer diagnoses in women [1]. Endometrial cancer constitutes the majority of uterine cancers. Despite multimodal treatment approaches, type I poorly differentiated endometrioid adenocarcinoma and type II cancers, including uterine serous papillary cancer (USPC) without estrogen receptor (ER) and progesterone receptor (PR) expression, have very poor prognosis unlike type I well-differentiated endometrioid adenocarcinoma, which expresses ER and PR. Among the systemic hormonal therapies considered for recurrent, metastatic, or high-risk disease, progestin is the most commonly used, mainly in the form of medroxyprogesterone acetate (MPA). However, clinical guidelines recommend that MPA may only be used for lower-grade endometrioid histology. This is based on previous reports that the highest response rates were noted in 
low-grade, ER-positive tumors of up to $55 \%$ [2,3]. In addition, long-term continuous use of progestin was known to cause a loss of effect of PR activation [2]. Therefore, development of a new treatment strategy for groups of cancer with poorer prognosis is urgent.

Recently, metformin, an oral biguanide anti-diabetic drug for type 2 diabetes, was shown to have significant anticancer activity and considered as a novel treatment option through drug repositioning [4], for several types of cancer including endometrial cancer [5-7]. However, it should be noted that almost all previous studies were conducted with supra-pharmacological concentrations (doses) of metformin, which were 10-100 times higher than maximally achievable therapeutic concentrations found in patients with type 2 diabetes mellitus [8]. Such levels exceed the maximum dose that could cause lactic acidosis, one of the most serious side effects of metformin. Any anticancer effect of metformin should be studied only in the condition of achievable therapeutic concentrations $[8,9]$.

Another approach for the development of novel anticancer drug regimens is the use of drug combinations. Although hormonal therapy is currently recommended only for lower-grade endometrioid histology in clinical guidelines, there is evidence suggesting that several anticancer mechanisms of progesteronal agents could show significant effects in poorly-differentiated endometrioid adenocarcinoma, as well as USPC [2,10,11], particularly when combined with metformin [12]. The purpose of this study was to evaluate the anticancer effect of tolerable doses of metformin with or without MPA as well as its underlying molecular mechanisms in endometrial cancer cells.

\section{Experimental Section}

\subsection{Cell Cultures}

Three human endometrial adenocarcinoma cell lines were used: Ishikawa (type I well-differentiated, $\mathrm{ER}+/ \mathrm{PR}+$ ), KLE (type I poorly differentiated, ER-/PR-), and USPC (type II serous papillary carcinoma, ER-/PR-) [13]. Ishikawa cells were purchased from the Japanese Collection of Research Bioresources cell bank (Osaka, Japan) and maintained in Dulbecco's Modified Eagle Medium (DMEM) (Life Technologies, Carlsbad, CA, USA) containing 10\% fetal bovine serum (FBS) (Hyclone, Logan, UT, USA), $50 \mu \mathrm{g} / \mathrm{mL}$ streptomycin, and $50 \mathrm{U} / \mathrm{mL}$ penicillin. KLE cells were obtained from the American Type Culture Collection (ATCC, Manassas, VA, USA). KLE was cultured in DMEM/F12 medium (Life Technologies) with $10 \% \mathrm{FBS}$ and $0.5 \% \mathrm{P} / \mathrm{S}$. USPC cells (USPC-ARK-1) were purchased from Dr. Alessandro Santin (Yale University, New Haven, CT, USA) and were cultured in Roswell Park Memorial Institute (RPMI)-1640 medium (Life Technologies) with 10\% FBS, $2 \mathrm{mM} / \mathrm{L}$ glutamine, and $0.5 \% \mathrm{P} / \mathrm{S}$. All the cells were cultured in an incubator at $37^{\circ} \mathrm{C}$ under a humidified atmosphere containing $5 \% \mathrm{CO}_{2}$.

\subsection{Dose Setup of Metformin and MPA Treatments}

The tolerable doses of metformin which could achieve a plasma concentration of around $1 \mathrm{mg} / \mathrm{L}$ was $500 \mathrm{mg}$ twice/day [14]. Although the maximal approved total daily dose of metformin for treatment of diabetes mellitus is $2.5 \mathrm{~g}$ ( $35 \mathrm{mg} / \mathrm{kg}$ body weight) [8], slow but progressive increase of fasting lactic acid levels were noted during metformin treatment with multiple doses from 100 to $850 \mathrm{mg}$ twice a day, suggesting that; the higher dose of metformin, the higher risk of lactic acidosis [14]. The therapeutic plasma concentrations of metformin measured in previous studies of type 2 diabetes ranged from 0.129 to $90 \mathrm{mg} / \mathrm{L}$ [9]. Therefore, $1 \mathrm{mM}(129.2 \mathrm{mg} / \mathrm{L})$ was set as a maximal concentration of metformin for our experiment, enabling the maximum achievable plasma concentration in a clinical setting without the risk of lactic acidosis.

MPA dose of $10 \mu \mathrm{M}$ was set based on a study of Zhang et al. [12] which also had evaluated the anticancer effect of MPA and metformin combination in endometrial cancer cells. MPA $10 \mu \mathrm{M}$ was high enough to inhibit proliferation of Ishikawa cells at $48 \mathrm{~h}$. However, it was too low to suppress progestin-resistant Ishikawa cells, which were considered to have similar characteristics with KLE cells in our study. Progestin resistance of progestin-resistant Ishikawa cells was overcome by the addition of metformin to MPA $10 \mu \mathrm{M}$ [12]. KLE and USPC cells were not expected to be susceptible to higher dose 
of MPA because of negative expression of ER and PR. Therefore, $10 \mu \mathrm{M}$ was set as an optimal dose of MPA which could show possible anticancer effects when combined with metformin in these cell lines. There was another study of progestin and metformin in endometrial cancer showed that $10 \mu \mathrm{M}$ MPA was the minimal dose that could significantly inhibit growth of RL95-2 cells $(E R+/ P R+)$ [15].

\subsection{Cell Counting and Cell Survival Analysis}

To measure cell growth rate, all cells were seeded in 12-well plates (Corning Life Sciences, New York, NY, USA) at 10,000 cells $/ \mathrm{cm}^{2}$, and the cell number was counted at 24-h intervals until $96 \mathrm{~h}$. For cell counting, the medium was removed from the cell culture plates, washed twice with phosphate buffer saline (PBS), and then treated with $0.25 \%$ trypsin for $5 \mathrm{~min}$ at $37^{\circ} \mathrm{C}$. The trypsin-treated cells were collected in a $15 \mathrm{~mL}$ tube, washed twice with the culture medium, and counted three times using the Adam-MC automatic cell counter (NanoEntek, city, Korea). Viable cells were more accurately measured using an advanced image analysis program of Adam-MC cell counter.

Cell survival analysis was performed to investigate the effects of metformin (Sigma-Aldrich, St. Louis, MO, USA) and/or MPA (Sigma-Aldrich) on endometrial cancer cell lines. Cells were seeded into a 96 well plate (Ishikawa $5 \times 10^{4} / \mathrm{cm}^{2}$, KLE $2 \times 10^{4} / \mathrm{cm}^{2}$ and USPC $3 \times 10^{4} / \mathrm{cm}^{2}$ ). The next day, cells were treated with $100 \mu \mathrm{M}$ and $1 \mathrm{mM}$ of metformin, with or without $10 \mu \mathrm{M}$ of MPA after media change. Then, survival rates of cells were analyzed after $24 \mathrm{~h}$ and $48 \mathrm{~h}$ of drug treatment using Ez-Cytox (DoGen Co., city, Korea), a water-soluble tetrazolium salt assay kit. The assay was performed according to the supplier protocol (http://www.dogenbio.com/shop/item.php?it_id=1490923054). The results were detected at $450 \mathrm{~nm}$ of absorbance.

\subsection{Western Blot}

The proteins collected from each cell sample were quantitated, subjected to $12 \%$ sodium dodecyl sulphate-polyacrylamide gel electrophoresis (SDS-PAGE), and then transferred to a nitrocellulose membrane. The membrane was subjected to blocking in PBS, containing 0.1\% Tween20 (Sigma, St. Louis, MO, USA) and 5\% skim milk (Invitrogen, Carlsbad, CA, USA), probed with primary antibodies, Glyceraldehyde 3-phosphate dehydrogenase (GAPDH) (14C10, Rabbit mAb), progesterone receptor-B (C1A2, Rabbit $\mathrm{mAb}), 5^{\prime}$ AMP-activated protein kinase $\alpha(\mathrm{AMPK} \alpha)(23 \mathrm{~A} 3$, Rabbit $\mathrm{mAb})$, phospho-AMPK $\alpha$ (Thr172, 40H9, Rabbit mAb) (Cell Signaling, Beverly, MA, USA), and erb-b2 receptor tyrosine kinase 2 (ErbB2) (Abcam, Cambridge, UK), and then reacted with peroxidase conjugated secondary antibody (Jackson Immuno Research, West Grove, PA, USA). Finally, target bands were visualized using SuperSignal chemiluminescent (ThermoFisher Scientific, Waltham, MA, USA). The immune-positive band was detected by Image software [16], which was used to analyze the gray value of the protein expression. All protein quantifications were adjusted for GAPDH levels.

\subsection{Cell Invasion Assay and ELISA}

To perform invasion assays, we first coated matrigel (BD Science, San Jose, CA, USA) on a transwell membrane with $8 \mu \mathrm{m}$ pores (Corning Life Sciences) at $37^{\circ} \mathrm{C}$ for $2 \mathrm{~h}$, and seeded $8 \times 10^{4} \mathrm{cells} / \mathrm{cm}^{2}$ into the transwell membrane. The next morning, the cells were starved for $2 \mathrm{~h}$ in culture medium without fetal bovine serum (FBS). The outside of the transwell was replaced with medium containing $5 \%$ charcoal strip FBS (ThermoFisher Scientific, Waltham, MA, USA) to induce invasion with or without anti-cancer drugs (metformin and MPA) and each $10 \mu \mathrm{M}$ inhibitor, MMP-2/9 inhibitor [17] (Sigma-Aldrich; Merck Millipore, Burlington, MA, USA) and TGF- $\beta$ inhibitor (Tocris Bioscience, Bristol, UK), for $24 \mathrm{~h}$ at $37^{\circ} \mathrm{C}$. The concentration of $10 \mu \mathrm{M}$ of the two inhibitors was chosen from previous studies [17-19]. The next day, all the cells in the transwells were removed using cotton buds, and the transwells were inverted to stain the transferred cells with $0.2 \%$ crystal violet. The stained cells were de-stained with $2 \%$ SDS and the supernatant was transferred into new 96 well plate. The absorbance was measured at $560 \mathrm{~nm}$.

For quantitative analysis of cell migration related proteins, the secretion levels of MMP-2 and -9 (R\&D Systems, MN, USA) and TGF- $\beta$ (R\&D Systems) were checked using ELISA kits. First, all cells 
were plated at $9 \times 10^{4}$ cells $/ \mathrm{cm}^{2}$ into a 24 well plate (Corning Life Sciences, NY, USA) and starved for $2 \mathrm{~h}$ in culture medium without FBS. The anticancer drugs were then treated at various concentrations while the culture medium was exchanged with the complete medium. After $24 \mathrm{~h}$, the cultures were collected without cells and analyzed. An ELISA was performed as per the supplier's instructions (https://www.rndsystems.com/).

\subsection{Statistical Analysis}

The statistical analyses were performed using GraphPad PRISM (GraphPad Software Inc., San Diego, CA, USA) and SPSS software (version 21.0; SPSS Inc., Chicago, IL, USA). Shapiro-Wilk test was used to check the distribution of data from three independent experiments and the test results confirmed that all data were normally distributed ( $p$ value $>0.05$ ). Therefore, means of the two groups were compared using a two-tailed unpaired Student's $t$-test. Bonferroni correction was performed for multiple testing correction and Bonferroni corrected $P$-values were used for statistical significance. Linear regression analysis was performed for estimating a trend of change. $P$-value $<0.05$ indicated statistical significance.

\section{Results}

\subsection{Cell Growth and Growth Inhibition by Tolerable Doses of Metformin and MPA in Endometrial Cancer Cell Lines}

We found that USPC cells had the fastest growth rate among the three endometrial cancer cells during 96-h incubation, followed by Ishikawa and KLE cells (Figure 1A,B).

(A)
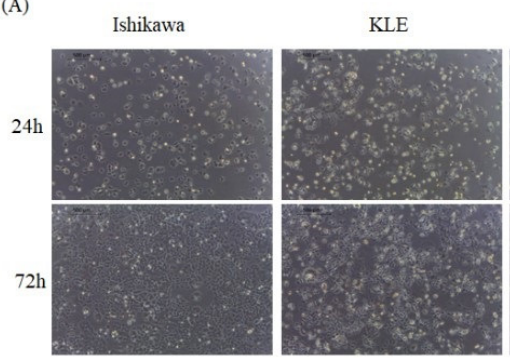

USPC

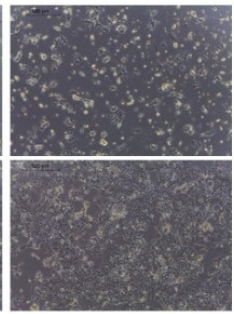

(B)

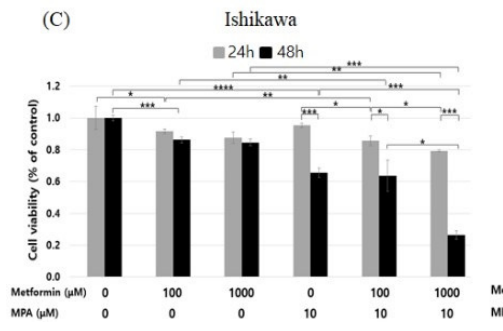

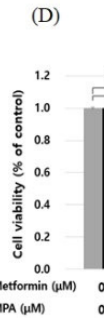

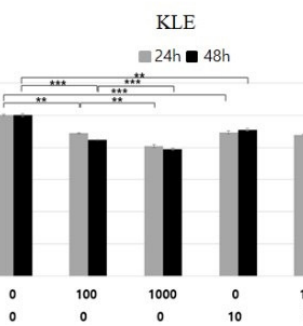

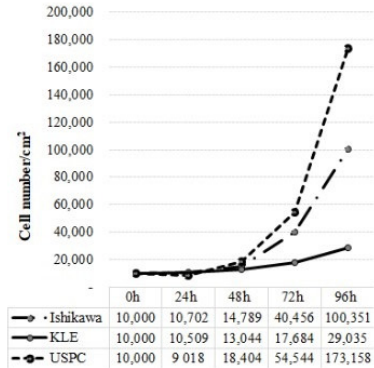

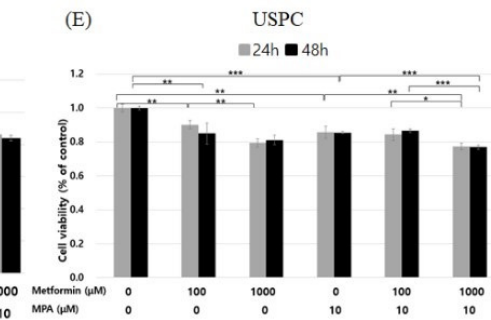

Figure 1. Cell growth and growth inhibition by metformin and medroxyprogesterone (MPA) in three endometrial cancer cell lines: Ishikawa, KLE, and USPC. (A) Cell morphology and number at 24 $\mathrm{h}$ and $72 \mathrm{~h}$, (B) cell growth rate $(0,24,48,72$, and $96 \mathrm{~h})$, cell viability after treatment of different dose combinations of MPA $(0,10 \mu \mathrm{M})$ and metformin $(0,100,1000 \mu \mathrm{M})$ in Ishikawa (C), KLE (D), and USPC cells (E). Each experiment was independently performed in triplicate: results are expressed as mean \pm standard deviation (C-E). Multiple testing correction was performed using Bonferroni adjustment and Bonferroni corrected p-values were used for statistical significance (C-E). ${ }^{*} p<0.05$, ${ }^{* *} p<0.005,{ }^{* * *} p<0.0005,{ }^{* * * *} p<0.00005$.

The MTT assay showed that treatment with metformin alone at $\leq 1000 \mu \mathrm{M}$ for $48 \mathrm{~h}$ exerted significant inhibitory effects on the cell viability of Ishikawa, KLE, and USPC cells in a dose-dependent, but not in a time-dependent manner (Figure 1C-E). In Ishikawa cells, a combination of metformin 
$(0,100,1000 \mu \mathrm{M})$ and $10 \mu \mathrm{M}$ MPA induced a significant decrease in cell viability in a time- and a dose-dependent manner (linear regression: $p<0.05$ ) (Figure 1C). Addition of $10 \mu \mathrm{M}$ MPA to metformin significantly inhibited cell viability compared to metformin alone at each dose $(0,100,1000 \mu \mathrm{M})$, respectively, in Ishikawa, but not in KLE and USPC cells.

\subsection{Changes in Expression Levels of PR and p-AMPKa by a Tolerable Dose of Metformin and MPA in Endometrial Cancer Cell Lines}

A significant level of endogenous expression of progesterone receptor-B (PR-B) was found in Ishikawa cells but not in KLE and USPC cells (Figure 2). In Ishikawa cells, metformin treatment alone induced the expression of PR-B in a dose-dependent manner, whereas metformin combined with $10 \mu \mathrm{M}$ MPA inhibited PR-B expression in a dose-dependent manner. Expression of activated form of AMPK $\alpha$, phospho-AMPK $\alpha$ (p-AMPK $\alpha$ ), was inhibited by metformin treatment alone in a dose-dependent manner $(0,100,1000 \mu \mathrm{M})$ in Ishikawa cells. However, p-AMPK $\alpha$ lost its dose-dependent pattern when Ishikawa cells were treated with a combination of metformin $(0,100,1000 \mu \mathrm{M})$ and $10 \mu \mathrm{M}$ MPA. In KLE and USPC cells, there were no significant changes in expression patterns of ErbB2, and AMPK $\alpha$ when treated with any of the doses of metformin and MPA. In AMPK/mammalian target of rapamycin (mTOR) pathway, high expression of p-AMPK $\alpha$ results in growth inhibition via inhibiting mTOR. Even though the expression of $\mathrm{p}-\mathrm{AMPK} \alpha$ was stronger when both metformin and MPA were used than when metformin was used alone in USPC cells (Figure 2), cell growths of the combination group were not significantly lower than those of metformin alone group (Figure 1E). In addition, there was no dose-dependent increase of $\mathrm{p}-\mathrm{AMPK} \alpha$ expression according to metformin doses $(0,100,1000 \mu \mathrm{M})$ in USPC cells (Figure 1E).

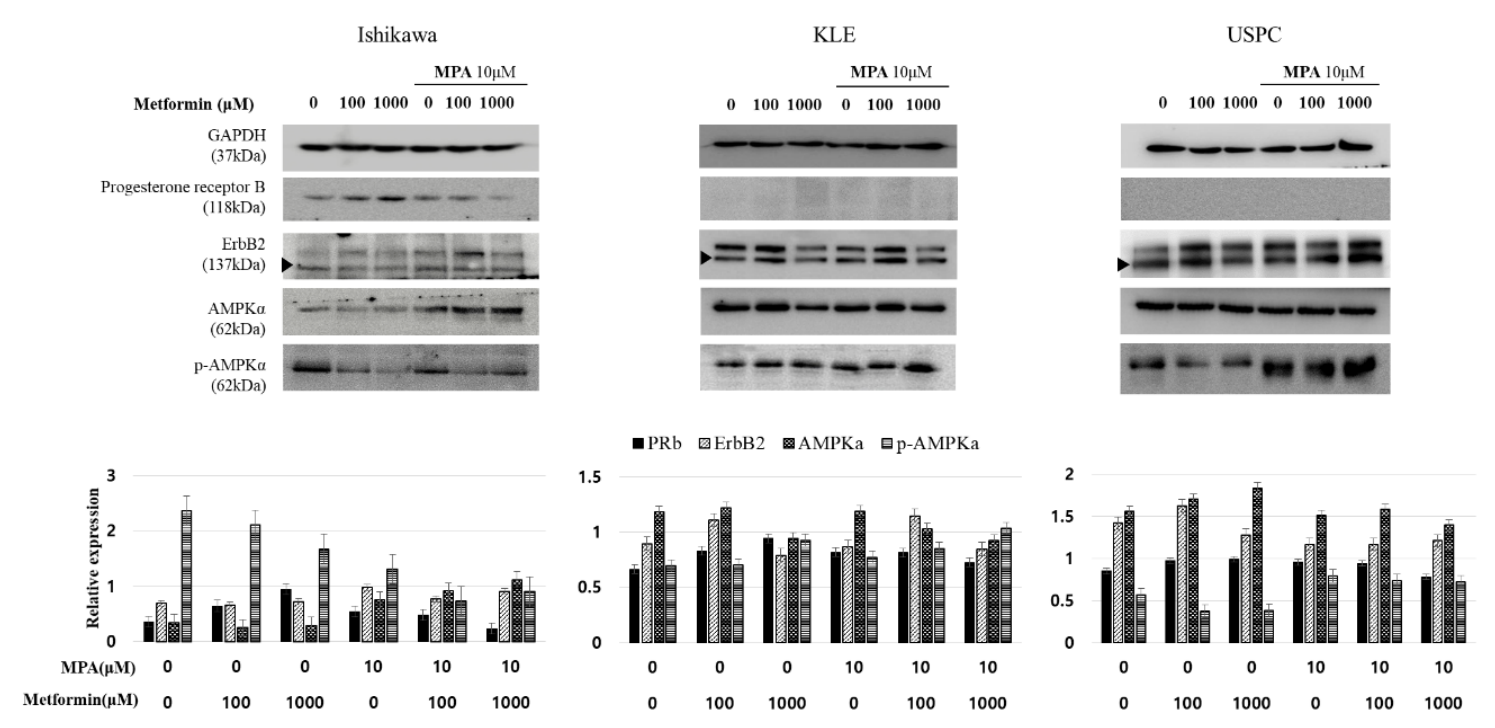

Figure 2. Expression of progesterone receptor B, ErbB2, AMPK $\alpha$, and phospho-AMPK $\alpha$ in three endometrial cancer cell lines (Ishikawa, KLE, and USPC) according to treatment with different dose combinations of medroxyprogesterone $(\mathrm{MPA})(0,10 \mu \mathrm{M})$ and metformin $(0,100,1000 \mu \mathrm{M})$. Band densities are quantified using Image $\mathrm{J}$ and values are presented as mean \pm S.E. of independent triplicates per group. Progesterone receptor B, ErbB2, and AMPK $\alpha$ were normalized to GAPDH, whilst p-AMPK $\alpha$ was normalized to $\mathrm{AMPK} \alpha$.

\subsection{Inhibition and Disinhibition of Cell Invasion by a Tolerable Dose of Metformin With or Without MPA in Endometrial Cancer Cell Lines}

We further performed an invasion assay (Figure 3A), which showed that metformin treatment alone did not induce any significant changes in cell invasion in Ishikawa and USPC cells (Figure 3B,D). In KLE cells (Figure 3C), however, metformin treatment alone significantly inhibited cell invasion 
in a dose-dependent manner $(1.31 \pm 0.05,0.94 \pm 0.04,0.83 \pm 0.05$ at $0,100 \mu \mathrm{M}, 1 \mathrm{mM}$, respectively; $p$ < 0.0005). Treatment with MPA $10 \mu \mathrm{M}$ alone significantly decreased the invasion of KLE cells compared to that of control cells $(1.31 \pm 0.05$ vs. $1.10 \pm 0.05 ; p<0.005)$. Interestingly, the inhibitory effect of metformin alone on cell invasion was reversed when metformin was combined with $10 \mu \mathrm{M}$ MPA $(1.10 \pm 0.05,1.42 \pm 0.18,1.41 \pm 0.26$ at $0,100,1000 \mu \mathrm{M}$, respectively; $p<0.005)$ (Figure 3C). In Ishikawa cells, by contrast, a combination of $10 \mu \mathrm{M}$ MPA with metformin exerted a significant inhibitory effect on cell invasion $(0.93 \pm 0.05,0.76 \pm 0.01,0.69 \pm 0.01$, at $0,10 \mu \mathrm{M}$ MPA alone, $100 \mu \mathrm{M}$ metformin and $10 \mu \mathrm{M}$ MPA, respectively; $p<0.0005)$, although the inhibitory effect on cell invasion of MPA and metformin combination disappeared at a metformin dose of $1000 \mu \mathrm{M}(0.84 \pm 0.08)$ (Figure 3B). There was no significant effect of metformin and MPA combination on the invasion of USPC cells (Figure 3D).

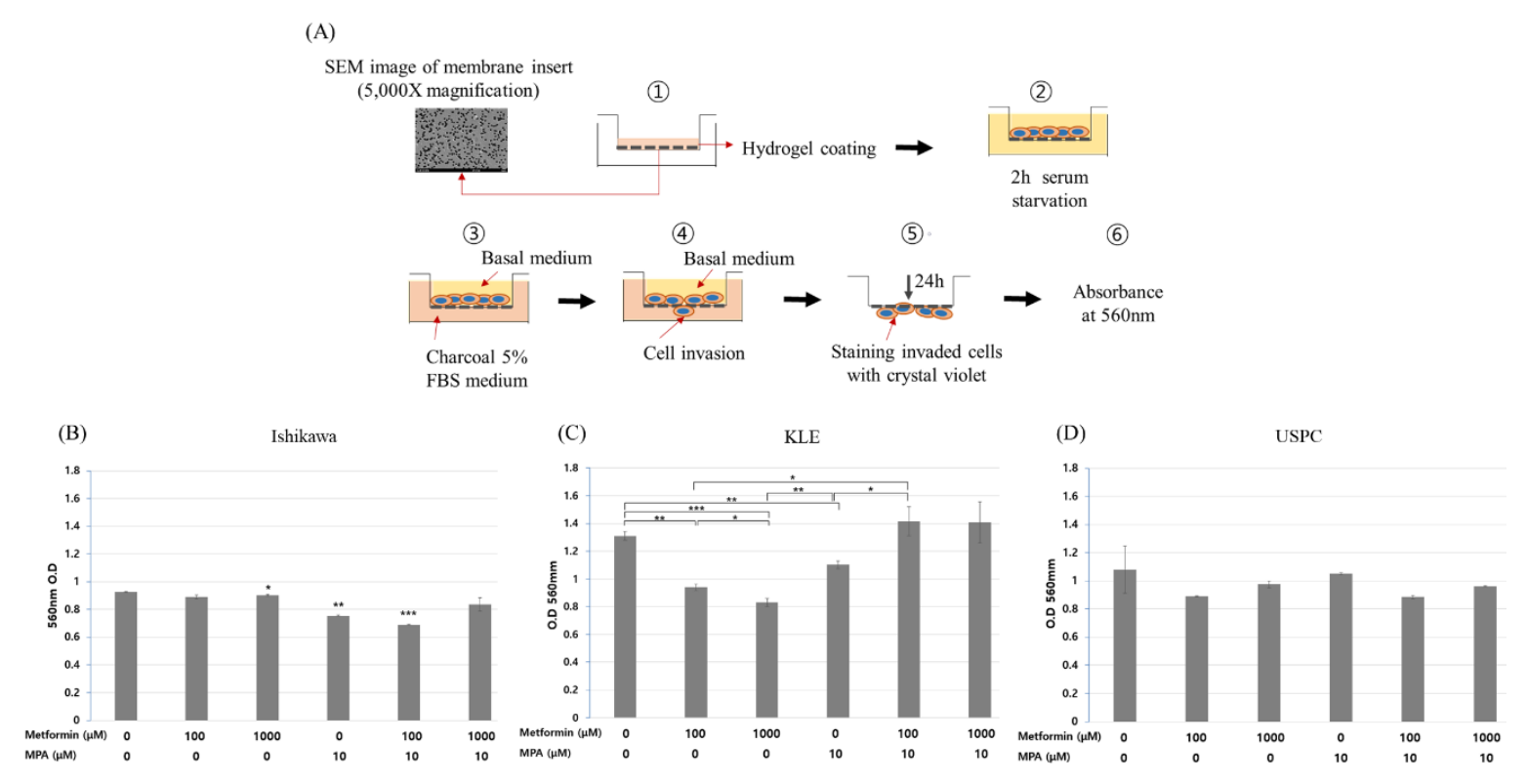

Figure 3. Invasion assay in three endometrial cancer cell lines (Ishikawa, KLE, and USPC). (A) The process of invasion assay, cell invasion after treatment of different dose combinations of medroxyprogesterone (MPA) $(0,10 \mu \mathrm{M})$ and metformin $(0,100,1000 \mu \mathrm{M})$ in Ishikawa (B), KLE (C), and USPC cells (D). (B) All comparisons were with control (no metformin/MPA). (B-D) Each experiment was independently performed in triplicate: results are expressed as mean \pm standard deviation. Multiple testing correction was performed using Bonferroni adjustment and Bonferroni corrected $\mathrm{p}$-values were used for statistical significance (B-D). ${ }^{*} p<0.05,{ }^{* *} p<0.005,{ }^{* * *} p<0.0005$.

3.4. MPA Reverses Tolerable Dose Metformin-Induced Inhibition of Invasion via MMP-9 and TGF- $\beta 1$ in KLE Endometrial Cancer Cells

MMP-2 showed no significant changes in response to the treatments in all three cell lines (Figure 4A-C). Despite a statistical insignificance, however, MMP-9 secretion was decreased with treatment of metformin alone $(0,100 \mu \mathrm{M})$ and increased with combined $10 \mu \mathrm{MPA}$ and metformin $(0,100,1000 \mu \mathrm{M})$. This change of MMP-9 secretion according to various dose combinations of MPA and metformin was the same as that of cell invasion in KLE cells when treated in combination with metformin $(0,100,1000 \mu \mathrm{M})$ and $10 \mu \mathrm{M}$ MPA $(3.99 \pm 0.90$ for control, $5.83 \pm 1.04,7.68 \pm 1.38$, $8.05 \pm 2.09 \mathrm{ng} / \mathrm{mL}$, respectively; $p<0.05$ ) (Figure $4 \mathrm{E}$ ). Otherwise, there were no significant changes in MMP-9 expression in Ishikawa and USPC cells (Figure 4D,F). TGF- $\beta 1$ also showed similar trends to MMP-9, which was in concordance with the change in cell invasion (Figure 5B). TGF- $\beta 1$ secretion was significantly decreased when KLE cells were treated with $1000 \mu \mathrm{M}$ metformin alone compared to that in control cells $(62.76 \pm 2.18$ vs. $54.19 \pm 3.60 \mathrm{pg} / \mathrm{mL} ; p=0.024)$. Furthermore, TGF- $\beta 1$ also exhibited the reverse pattern when treated with a combination of $1000 \mu \mathrm{M}$ metformin and $10 \mu \mathrm{M}$ MPA $(62.76 \pm 2.18$ vs. $77.52 \pm 5.95 ; p=0.016)$. There were no significant changes in TGF- $\beta 1$ levels according 
to the treatments in Ishikawa and USPC cells (Figure 5A,C). We showed that the reversal of $1 \mathrm{mM}$ metformin-induced inhibition of invasion by the treatment of $10 \mu \mathrm{M}$ MPA was significantly inhibited again after treatment of MMP-2/9 inhibitor and/or TGF- $\beta$ inhibitor. The effect of MMP-2/9 inhibitor was greater than that of TGF- $\beta$ inhibitor (Figure 6). This finding implies that reversal of anti-invasive effect of metformin by the addition of MPA in KLE cells might be associated with MMP-9 and TGF- $\beta 1$.
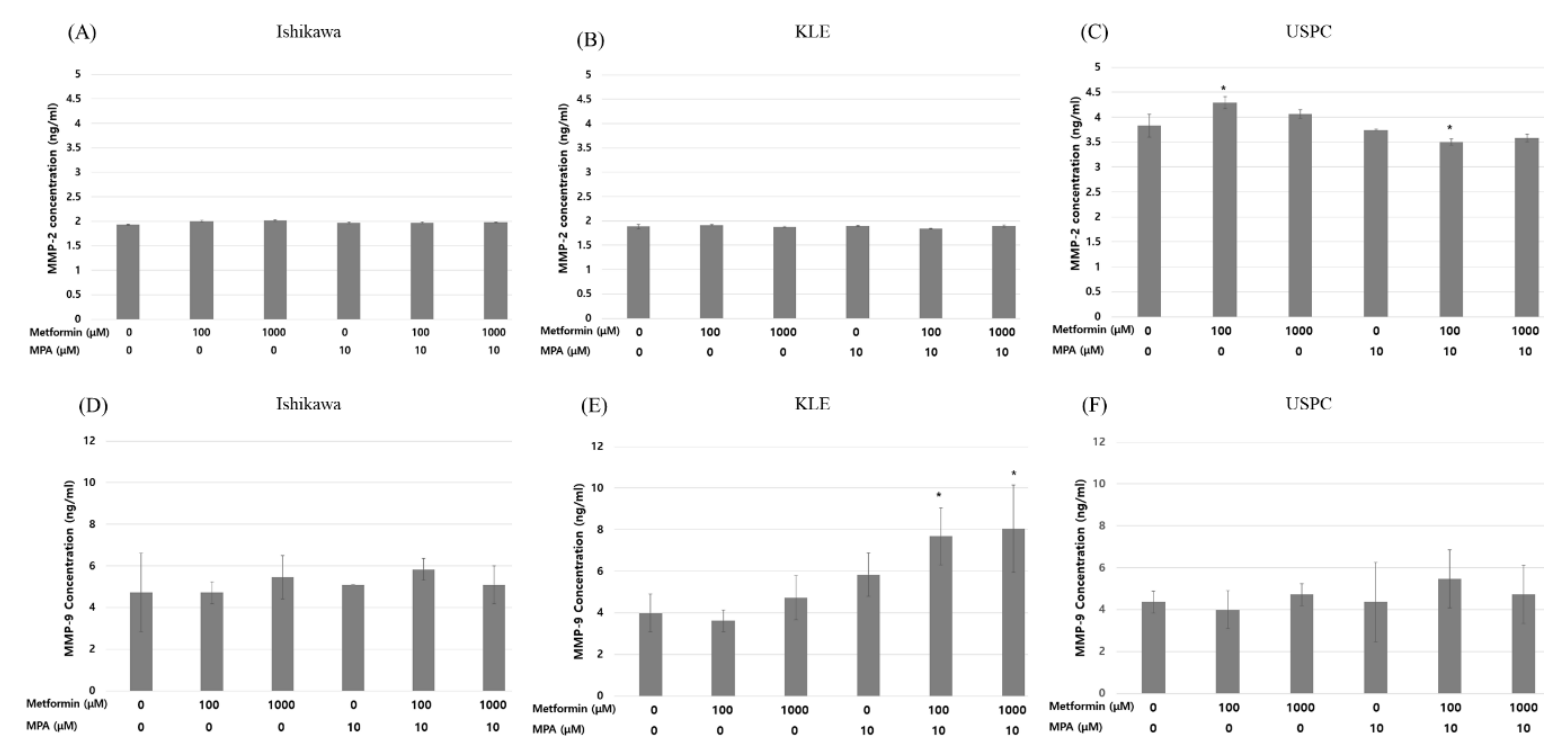

KLE

(F)

USPC

Figure 4. Matrix metallopeptidase (MMP)-2 (A, Ishikawa; B, KLE; C, USPC) and MMP-9 (D, Ishikawa; E, KLE, F, USPC) in three endometrial cancer cell lines after treatment with different dose combinations of medroxyprogesterone (MPA) $(0,10 \mu \mathrm{M})$ and metformin $(0,100,1000 \mu \mathrm{M})$. Each experiment was independently performed in triplicate: results are expressed as mean \pm standard deviation. Multiple testing correction was performed using Bonferroni adjustment and Bonferroni corrected p-values were used for statistical significance. ${ }^{*} p<0.05$.
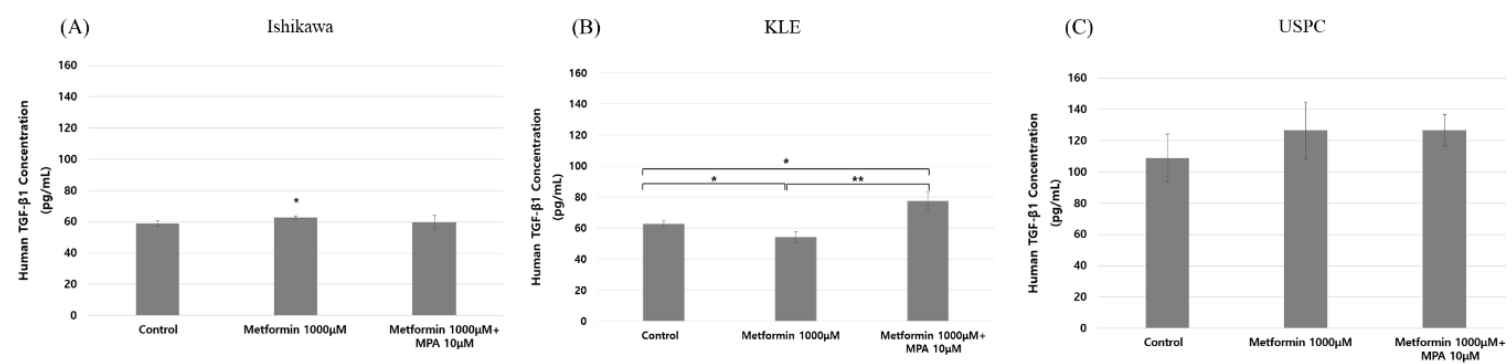

Figure 5. Transforming growth factor (TGF)- $\beta 1$ in three endometrial cancer cell lines after treatment with different dose combinations of medroxyprogesterone (MPA) $(0,10 \mu \mathrm{M})$ and metformin $(0,1000 \mu \mathrm{M})$ in Ishikawa (A), KLE (B), and USPC cells (C). Each experiment was independently performed in triplicate: results are expressed as mean \pm standard deviation. Multiple testing correction was performed using Bonferroni adjustment and Bonferroni corrected $p$-values were used for statistical significance. ${ }^{*} p<0.05,{ }^{* *} p<0.005$. 


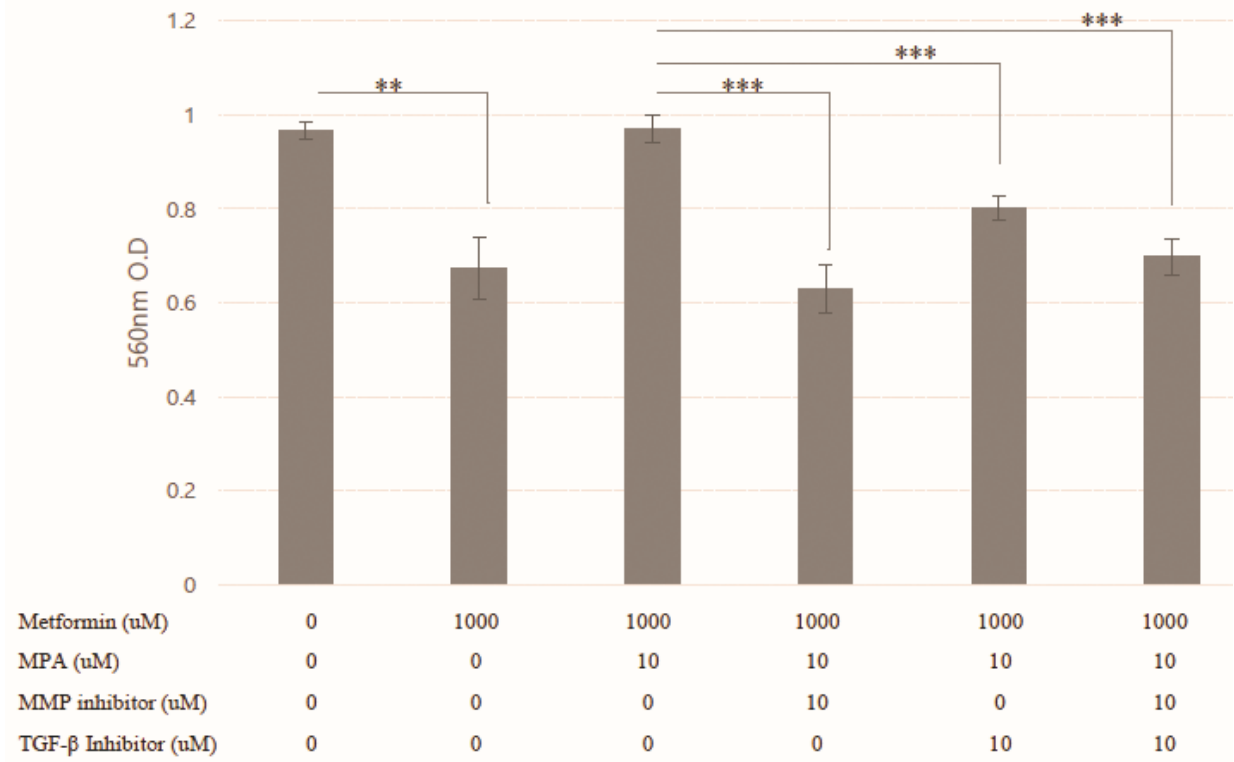

Figure 6. Cell invasion after combination treatment of $1 \mathrm{mM}$ metformin (Met), $10 \mu \mathrm{M}$ medroxyprogesterone (MPA), $10 \mu \mathrm{M}$ Matrix metallopeptidase (MMP) inhibitor and transforming growth factor (TGF)- $\beta$ inhibitor in KLE cell lines. Each experiment was independently performed in triplicate: results are expressed as mean \pm standard deviation. Multiple testing correction was performed using Bonferroni adjustment and Bonferroni corrected $p$-values were used for statistical significance. ${ }^{* *} p<0.005,{ }^{* * *} p<0.0005$.

\section{Discussion}

Our study results suggest that the anticancer effects of tolerable doses of metformin varied according to the cell types and the presence of combinations with MPA in endometrial cancer. Metformin alone $\leq 1000 \mu \mathrm{M}$ had anti-invasive effects on KLE cells, however, the anti-invasive effect of metformin is even reversed by the addition of $10 \mu \mathrm{M}$ MPA. Changes in the expression of MMP-9 and TGF- $\beta 1$ might be associated with these findings. We also showed that tolerable doses of metformin alone $\leq 1000 \mu \mathrm{M}$ inhibited cell proliferation of Ishikawa, KLE, and USPC cells in a dose-dependent manner. However, there was no additional anti-proliferative effect of metformin $\leq 1000 \mu \mathrm{M}$ and MPA co-treatment in KLE and USPC cells.

MPA is recommended as a fertility-preserving treatment for young endometrial cancer patients, as well as palliative treatment for terminally ill patients with hormone receptor-positive cancer, especially with PR; most of the MPA anticancer effects are known to act through the interaction with PR [20]. However, response rates of MPA are unsatisfying because of the appearance of progesterone resistance; efforts were made to find an effective way to overcome this [12,20,21].

Metformin was suggested to combine with MPA based on several mechanisms of reversing progesterone resistance. Mitsuhashi et al. [22] demonstrated that the combination of MPA and metformin had significantly better prognosis than MPA alone in the patients with endometrial hyperplasia or cancer (3-year relapse-free survival, $79.3 \%$ vs. $45.2 \% ; p=0.031$ ). And this prognosis benefit of MPA and metformin combination over MPA alone was more prominent for obese patients $\left(B M I \geq 25 \mathrm{~kg} / \mathrm{m}^{2}\right)$ than non-obese patients $\left(\mathrm{BMI}<25 \mathrm{~kg} / \mathrm{m}^{2}\right)$ through inhibiting the phosphatidylinositol 3-kinase (PI3K)-protein kinase B (AKT)-mTOR pathway by activating AMPK, a master regulator of cellular energy homeostasis AMPK and the PI3K-AKT-mTOR pathway is known as one of the most commonly dysregulated signaling pathways in endometrial cancer [23]. One of the proposed mechanisms of action of metformin is through inhibition of complex I in the mitochondria, resulting in activation of AMPK., which then suspends ATP-consuming processes including protein synthesis, 
such as inhibiting mTOR. Therefore, metformin is thought as a mTOR inhibitor to reduce cellular proliferation in various type of cancer cell lines including endometrial cancer [23].

However, there were two issues to be solved. One was the supra-therapeutic concentration of metformin. The activation of AMPK was almost always demonstrated at an unrealistically high supra-therapeutic concentration of metformin, considering the maximal dose in humans (without the risk of serious side effects) $[21,23,24]$. An experiment of Dr. Sivalingam showed that the expressions of $\mathrm{p}$-AMPK $\alpha$ at metformin $<2 \mathrm{mM}$ were weak and there was no significant decrease of cell viability at metformin $<1 \mathrm{mM}$ in Ishikawa, HEC1A, and KLE cells [23]. A recently published randomized controlled study in human reported that short-term treatment of standard diabetic doses $(850 \mathrm{mg}$ per day for 3 days, and twice daily thereafter) of metformin did not reduce tumor proliferation in women with endometrial cancer awaiting hysterectomy [25]. The results did not support a biological effect of diabetic dose of metformin as well as clinical application in women with endometrial cancer. The other issue was that most of the findings were true only in Ishikawa cells, but not in other types of cells, for example, KLE [12]. Therefore, we tried to find any anti-cancer effects of tolerable doses of metformin with or without MPA in endometrial cancer cells with non-favorable clinical behavior.

We found that metformin alone at $\leq 1000 \mu \mathrm{M}$ significantly inhibited the proliferation of all three cell lines (Figure 1C-E and Figure 2). The anti-proliferative effect of metformin alone at $\leq 1000 \mu \mathrm{M}$ in PR-positive Ishikawa cells might be mediated through PR-B. This is because the expression of PR-B but not of $\mathrm{p}$-AMPK- $\alpha$ increased in a dose-dependent manner with metformin treatment (Figure 2). Xie et al. [20] also demonstrated metformin significantly increased PR mRNA and protein levels in Ishikawa cells. On the other hand, growth inhibition by low-dose metformin alone of KLE and USPC cells and the enhanced anti-proliferative effect of metformin in combination with MPA in Ishikawa cells were neither associated with PR-B nor with the AMPK-dependent pathway because there were no corresponding changes in their expression levels (Figure 2). The plausible mechanism underlying this enhanced anti-proliferative effect of the metformin and MPA combination on Ishikawa cells could include AMPK-independent pathways, including factors of the Rag family of GTPases, hypoxia inducible factor (HIF) target gene, and regulated in development and the DNA damage response I (REDD1) [24]. Dr. Sivalingam also suggested that metformin might be acting through AMPK-independent pathways to inhibit mTOR in HEC1A cells based on the findings that the decreased phosphorylation of eukaryotic translation initiation factor 4E-binding protein-1 (4EBP-1) and S6, an immediate downstream target of AMPK, occurred prior to AMPK activation [23]. Other studies confirmed that there was no significant increase in p-AMPK $\alpha$ expression at low doses of metformin, $\leq 1000 \mu \mathrm{M}$, in Ishikawa, KLE, and USPC cells [23,26,27]. In these studies, high dose metformin $\geq 10 \mathrm{mM}$ was shown to be necessary to bring about a significant increase in p-AMPK $\alpha$ expression. As there were no significant changes in PR and p-AMPK $\alpha$ levels in KLE and USPC cells when metformin was combined with MPA (Figure 2), we moved our focus towards invasion; the plausible invasion mechanism was not related to the activation of AMPK.

It was interesting that the dose-dependent inhibitory effect of metformin $\leq 1000 \mu \mathrm{M}$ on cell invasion was found only in KLE cells, but not in Ishikawa and USPC cells. It was even more interesting that the addition of MPA to metformin resulted in the opposite effects on cell invasion in the two different types of cells, i.e., reversing metformin effect in KLE and enhancing metformin effect in Ishikawa cells (Figure 3B,C). The finding of low dose metformin alone not conferring any change in invasion capability of Ishikawa cells was consistent with that in a study of de Barros Machado et al. [28]. Even though we could not find a plausible molecular mechanism for the enhanced anti-invasive effect of the narrow dose window of metformin $(0-100 \mu \mathrm{M})$ and MPA combination in Ishikawa cells (Figure 3B), it is notable that MMP-9 and TGF- $\beta 1$ showed the same pattern of change to that of cell invasion only in KLE cells (Figures 4 and 5).

Classically, MMPs are thought to facilitate cancer invasion and metastasis actively due to its ability to degrade extra-cellular matrix clearing a path for tumor cells to move through matrix barriers [29]. Among the MMPs, MMP-2 (gelatinase A), and MMP-9 (gelatinase B) are the most essential in 
degrading of type IV collagen, which is the main constituent of the basement membrane [30]. High expression of both MMP-2 and 9, which was observed in endometrial carcinomas, was associated with parameters of tumor aggressiveness, including advanced stage, metastasis, and lymphovascular invasion [31]. TGF- $\beta$ is known to play a crucial role in the initial steps of cancer invasion associated with epithelial-mesenchymal transition (EMT) process and the acquisition of an invasive/migratory phenotype during myometrial infiltration and metastasis in endometrial cancer $[30,32,33]$. Therefore, we decided to look at MMP-2, MMP-9 and TGF- $\beta$ for the plausible underlying mechanisms for the anti-invasive effect of metformin as well as its reversal effect in the addition of MPA [19,31,32,34].

Samarnthai et al. [35] reported the dualistic model of endometrial carcinoma, type I and type II, in terms of genetic changes and clinical behavior. KLE cells could be clinically characterized as type II cancer cells because of the aggressive behavior and poor outcomes, but also as type I due to the frequent PTEN and KRAS mutations and rare p53 mutation, which are typical in type I cancer. Zhang et al. showed that the expression of glyoxalase I (GloI) was significantly higher in KLE cells than Ishikawa cells, suggesting GloI might be involved in progestin resistance in KLE cells [12]. They reported metformin could reverse progestin resistance by downregulating GloI expression. Regarding cell invasion and migration, Wen et al. demonstrated that suppression of golgi phosphoprotein 3 (GOLPH3), a novel oncogene, of which the expression was the highest among four endometrial cancer cell lines (HEC1A, KLE, RL95-2, and Ishikawa), using shGOLPH3 could reduce KLE cell proliferation, migration, and invasion while accelerating apoptosis [36]. Furthermore, they found that the number of nude mice with distant metastasis was smaller in KLE-shGOLPH3 injection mice group (4/7) than that in control KLE injection group (7/7).

Despite a small number of studies, so far, addressing the anti-invasive and/or anti-migratory effects of metformin in endometrial cancer cells, this study is, to the best of our knowledge, the first study which showed that the significant anti-invasive effect of a tolerable dose of metformin in KLE cells was completely reversed to the state of no treatment by the addition of MPA; these findings might be mediated through MMP-9 and TGF- $\beta 1$. However, our study has some limitations firstly in that metformin was not shown as an AMPK activator. There are a few studies which did not support metformin as a potent AMPK activator, not only in proliferation [23,26], but also in invasion [19]. Secondly, given the continuously decreasing trend of KLE cell invasion with the increase of metformin dose $(0,100,1000 \mu \mathrm{M}), \mathrm{MMP}-9$ concentration at $1000 \mu \mathrm{M}$ metformin only was expected to be lower than that of $100 \mu \mathrm{M}$ metformin. Thirdly, the effects of MMP-2/9 or TGF- $\beta$ inhibitor alone on cell invasion were not shown (Figure 6). It could weaken our conclusion on the molecular mechanism of reversal of anti-invasive effect of metformin by the addition of MPA in KLE cells. Lastly, study results only from in vitro experiments without supportive in vivo animal study kept us from drawing a firm conclusion.

Most studies on metformin and MPA in endometrial cancer have concluded that combining the two could be a potential therapeutic strategy for overcoming progesterone resistance [12,20]. However, our study suggests the possibility of the combination being harmful instead of beneficial in some conditions, especially in clinically highly aggressive cancers but genetically classified as type I. Further animal studies are required to clinically confirm our study findings.

Author Contributions: Conceptualization, D.H.S. and N.H.P.; Methodology, L.S., H.-S.P.; Formal Analysis, D.H.S., L.S., H.-S.P.; Resources, D.H.S.; Data Curation, D.H.S. and S.L.; Writing-Original Draft Preparation, D.H.S. and S.L.; Writing-Review \& Editing, D.H.S., S.L., H.-S.P., N.H.P.; Visualization, D.H.S. and S.L.; Supervision, H.-S.P. and N.H.P.; Project Administration, N.H.P. All authors have read and agreed to the published version of the manuscript.

Funding: This research received no external funding.

Acknowledgments: This research did not receive any specific grant from funding agencies in the public, commercial, or not-for-profit sectors.

Conflicts of Interest: The authors declare no conflict of interest. 


\section{References}

1. Siegel, R.L.; Miller, K.D.; Jemal, A. Cancer statistics, 2018. CA Cancer J. Clin. 2018, 68, 7-30. [CrossRef] [PubMed]

2. Singh, M.; Zaino, R.J.; Filiaci, V.J.; Leslie, K.K. Relationship of estrogen and progesterone receptors to clinical outcome in metastatic endometrial carcinoma: A Gynecologic Oncology Group Study. Gynecol. Oncol. 2007, 106, 325-333. [CrossRef] [PubMed]

3. Ushijima, K.; Yahata, H.; Yoshikawa, H.; Konishi, I.; Yasugi, T.; Saito, T.; Nakanishi, T.; Sasaki, H.; Saji, F.; Iwasaka, T.; et al. Multicenter phase II study of fertility-sparing treatment with medroxyprogesterone acetate for endometrial carcinoma and atypical hyperplasia in young women. J. Clin. Oncol. 2007, 25, 2798-2803. [CrossRef] [PubMed]

4. Kobayashi, Y.; Banno, K.; Kunitomi, H.; Tominaga, E.; Aoki, D. Current state and outlook for drug repositioning anticipated in the field of ovarian cancer. J. Gynecol. Oncol. 2019, 30, e10. [CrossRef] [PubMed]

5. Perez-Lopez, F.R.; Pasupuleti, V.; Gianuzzi, X.; Palma-Ardiles, G.; Hernandez-Fernandez, W.; Hernandez, A.V. Systematic review and meta-analysis of the effect of metformin treatment on overall mortality rates in women with endometrial cancer and type 2 diabetes mellitus. Maturitas 2017, 101, 6-11. [CrossRef]

6. Laskov, I.; Drudi, L.; Beauchamp, M.C.; Yasmeen, A.; Ferenczy, A.; Pollak, M.; Gotlieb, W.H. Anti-diabetic doses of metformin decrease proliferation markers in tumors of patients with endometrial cancer. Gynecol. Oncol. 2014, 134, 607-614. [CrossRef]

7. Nevadunsky, N.S.; Van Arsdale, A.; Strickler, H.D.; Moadel, A.; Kaur, G.; Frimer, M.; Conroy, E.; Goldberg, G.L.; Einstein, M.H. Metformin use and endometrial cancer survival. Gynecol. Onco.l 2014, 132, 236-240. [CrossRef]

8. He, L.; Wondisford, F.E. Metformin action: Concentrations matter. Cell Metab. 2015, 21, 159-162. [CrossRef] [PubMed]

9. Kajbaf, F.; De Broe, M.E.; Lalau, J.D. Therapeutic Concentrations of Metformin: A Systematic Review. Clin. Pharmacokinet. 2016, 55, 439-459. [CrossRef]

10. Guy, M.S.; Qamar, L.; Behbakht, K.; Post, M.D.; Sheeder, J.; Sartorius, C.A.; Spillman, M.A. Progestin treatment decreases CD133+ cancer stem cell populations in endometrial cancer. Gynecol. Oncol. 2016, 140, 518-526. [CrossRef]

11. Bokhari, A.A.; Lee, L.R.; Raboteau, D.; Hamilton, C.A.; Maxwell, G.L.; Rodriguez, G.C.; Syed, V. Progesterone inhibits endometrial cancer invasiveness by inhibiting the TGFbeta pathway. Cancer Prev. Res. 2014, 7, 1045-1055. [CrossRef] [PubMed]

12. Zhang, Z.; Dong, L.; Sui, L.; Yang, Y.; Liu, X.; Yu, Y.; Zhu, Y.; Feng, Y. Metformin reverses progestin resistance in endometrial cancer cells by downregulating GloI expression. Int. J. Gynecol. Cancer. 2011, 21, 213-221. [CrossRef]

13. Zhou, X.; Wang, Z.; Zhao, Y.; Podratz, K.; Jiang, S. Characterization of sixteen endometrial cancer cell lines. In Proceedings of the AACR Annual Meeting, Los Angeles, CA, USA, 14-18 April 2007.

14. Hong, Y.; Rohatagi, S.; Habtemariam, B.; Walker, J.R.; Schwartz, S.L.; Mager, D.E. Population exposure-response modeling of metformin in patients with type 2 diabetes mellitus. J. Clin. Pharmacol. 2008, 48, 696-707. [CrossRef] [PubMed]

15. Cao, C.; Zhou, J.Y.; Xie, S.W.; Guo, X.J.; Li, G.T.; Gong, Y.J.; Yang, W.J.; Li, Z.; Zhong, R.H.; Shao, H.H.; et al. Metformin Enhances Nomegestrol Acetate Suppressing Growth of Endometrial Cancer Cells and May Correlate to Downregulating mTOR Activity In Vitro and In Vivo. Int. J. Mol. Sci. 2019, 20, 3308. [CrossRef] [PubMed]

16. Schneider, C.A.; Rasband, W.S.; Eliceiri, K.W. NIH Image to ImageJ: 25 years of image analysis. Nat. Methods 2012, 9, 671-675. [CrossRef]

17. Asghar, M.Y.; Kemppainen, K.; Lassila, T.; Tornquist, K. Sphingosine 1-phosphate attenuates MMP2 and MMP9 in human anaplastic thyroid cancer C643 cells: Importance of S1P2. PLoS ONE 2018, 13, e0196992. [CrossRef]

18. Halder, S.K.; Beauchamp, R.D.; Datta, P.K. A specific inhibitor of TGF-beta receptor kinase, SB-431542, as a potent antitumor agent for human cancers. Neoplasia 2005, 7, 509-521. [CrossRef]

19. Tan, B.K.; Adya, R.; Chen, J.; Lehnert, H.; Sant Cassia, L.J.; Randeva, H.S. Metformin treatment exerts antiinvasive and antimetastatic effects in human endometrial carcinoma cells. J. Clin. Endocrinol. Metab. 2011, 96, 808-816. [CrossRef]

20. Xie, Y.; Wang, Y.L.; Yu, L.; Hu, Q.; Ji, L.; Zhang, Y.; Liao, Q.P. Metformin promotes progesterone receptor expression via inhibition of mammalian target of rapamycin (mTOR) in endometrial cancer cells. J. Steroid Biochem. Mol. Biol. 2011, 126, 113-120. [CrossRef] 
21. Zhuo, Z.; Wang, A.; Yu, H. Metformin targeting autophagy overcomes progesterone resistance in endometrial carcinoma. Arch. Gynecol. Obstet. 2016, 294, 1055-1061. [CrossRef]

22. Mitsuhashi, A.; Habu, Y.; Kobayashi, T.; Kawarai, Y.; Ishikawa, H.; Usui, H.; Shozu, M. Long-term outcomes of progestin plus metformin as a fertility-sparing treatment for atypical endometrial hyperplasia and endometrial cancer patients. J. Gynecol. Oncol. 2019, 30, e90. [CrossRef]

23. Sivalingam, V.N. The Role of Metformin in Obesity-Driven Endometrial Cancer. Available online: https:/www.research.manchester.ac.uk/portal/en/theses/the-role-of-metformin-in-obesitydriven-endometrialcancer(5a4418b9-5dab-4e6a-be05-9180996073c1).html (accessed on 3 November 2020).

24. Sivalingam, V.N.; Myers, J.; Nicholas, S.; Balen, A.H.; Crosbie, E.J. Metformin in reproductive health, pregnancy and gynaecological cancer: Established and emerging indications. Hum. Reprod. Update 2014, 20, 853-868. [CrossRef]

25. Kitson, S.J.; Maskell, Z.; Sivalingam, V.N.; Allen, J.L.; Ali, S.; Burns, S.; Gilmour, K.; Latheef, R.; Slade, R.J.; Pemberton, P.W.; et al. PRE-surgical Metformin In Uterine Malignancy (PREMIUM): A Multi-Center, Randomized Double-Blind, Placebo-Controlled Phase III Trial. Clin. Cancer Res. 2019, 25, 2424-2432. [CrossRef]

26. Liu, Z.; Qi, S.; Zhao, X.; Li, M.; Ding, S.; Lu, J.; Zhang, H. Metformin inhibits 17beta-estradiol-induced epithelial-to-mesenchymal transition via betaKlotho-related ERK1/2 signaling and AMPKalpha signaling in endometrial adenocarcinoma cells. Oncotarget 2016, 7, 21315-21331. [CrossRef]

27. Sarfstein, R.; Friedman, Y.; Attias-Geva, Z.; Fishman, A.; Bruchim, I.; Werner, H. Metformin downregulates the insulin/IGF-I signaling pathway and inhibits different uterine serous carcinoma (USC) cells proliferation and migration in p53-dependent or -independent manners. PLoS ONE 2013, 8, e61537. [CrossRef]

28. de Barros Machado, A.; Dos Reis, V.; Weber, S.; Jauckus, J.; Brum, I.S.; von Eye Corleta, H.; Strowitzki, T.; Capp, E.; Germeyer, A. Proliferation and metastatic potential of endometrial cancer cells in response to metformin treatment in a high versus normal glucose environment. Oncol. Lett. 2016, 12, 3626-3632. [CrossRef] [PubMed]

29. Quintanilla, M.; Castillo, G.d.; Kocic, J.; Santibáñez, J.F. TGF- $\beta$ and MMPs: A complex regulatory loop involved in tumor progression. In Matrix Metalloproteinases: Biology, Functions and Clinical Implications; Oshiro, N., Miyagi, E., Eds.; Nova Science: Runcorn, UK, 2012; pp. 1-38.

30. Chang, C.C.; Ling, X.H.; Hsu, H.F.; Wu, J.M.; Wang, C.P.; Yang, J.F.; Fang, L.W.; Houng, J.Y. Siegesbeckia orientalis Extract Inhibits TGFbeta1-Induced Migration and Invasion of Endometrial Cancer Cells. Molecules 2016, 21, 1021. [CrossRef]

31. Liu, C.; Li, Y.; Hu, S.; Chen, Y.; Gao, L.; Liu, D.; Guo, H.; Yang, Y. Clinical significance of matrix metalloproteinase-2 in endometrial cancer: A systematic review and meta-analysis. Medicine 2018, 97, e10994. [CrossRef]

32. Muinelo-Romay, L.; Colas, E.; Barbazan, J.; Alonso-Alconada, L.; Alonso-Nocelo, M.; Bouso, M.; Curiel, T.; Cueva, J.; Anido, U.; Forteza, J.; et al. High-risk endometrial carcinoma profiling identifies TGF-beta1 as a key factor in the initiation of tumor invasion. Mol. Cancer Ther. 2011, 10, 1357-1366. [CrossRef]

33. Bokhari, A.A.; Baker, T.M.; Dorjbal, B.; Waheed, S.; Zahn, C.M.; Hamilton, C.A.; Maxwell, G.L.; Syed, V. Nestin suppression attenuates invasive potential of endometrial cancer cells by downregulating TGF-beta signaling pathway. Oncotarget 2016, 7, 69733-69748. [CrossRef]

34. Nakamura, K.; Kodama, J.; Hongo, A.; Hiramatsu, Y. Role of emmprin in endometrial cancer. BMC Cancer 2012, 12, 191. [CrossRef]

35. Samarnthai, N.; Hall, K.; Yeh, I.T. Molecular profiling of endometrial malignancies. Obstet. Gynecol. Int. 2010, 2010, 162363. [CrossRef]

36. Wen, Y.; Tan, X.; Wu, X.; Wu, Q.; Qin, Y.; Liang, M.; Ran, G.; Gu, H.; Xie, R. Golgi phosphoprotein 3 (GOLPH3) promotes endometrial carcinoma cell invasion and migration by regulating the epithelial-mesenchymal transition. Cancer Biomark 2019, 26, 21-30. [CrossRef]

Publisher's Note: MDPI stays neutral with regard to jurisdictional claims in published maps and institutional affiliations. 